\title{
Safety Analysis of Dual Purpose Metal Cask Subjected to Impulsive Loads due to Aircraft Engine Crash*
}

\author{
Koji SHIRAI $^{* *}$, Kosuke NAMBA $^{* *}$ and Toshiari SAEGUSA ${ }^{* *}$ \\ ${ }^{* *}$ Central Research Institute of Electric Power Industry, \\ 1646, Abiko, Abiko-shi, Chiba-ken, Japan \\ E-mail: shirai@criepi.denken.or.jp
}

\begin{abstract}
In Japan, the first Interim Storage Facility of spent nuclear fuel away from reactor site is being planned to start its commercial operation around 2010, in use of dual-purpose metal cask in the northern part of Main Japan Island. Business License Examination for safety design approval has started since March, 2007. To demonstrate the more scientific and rational performance of safety regulation activities on each phase for the first license procedure, CREPEI has executed demonstration tests with full scale casks, such as drop tests onto real targets without impact limiters ${ }^{(1)}$ and seismic tests subjected to strong earthquake motions ${ }^{(2)}$. Moreover, it is important to develop the knowledge for the inherent security of metal casks under extreme mechanical-impact conditions, especially for increasing interest since the terrorist attacks from 11th September 2001 ${ }^{(3)-(6)}$. This paper presents dynamic mechanical behavior of the metal cask lid closure system caused by direct aircraft engine crash and describes calculated results (especially, leak tightness based on relative dynamic displacements between metallic seals). Firstly, the local penetration damage of the interim storage facility building by a big passenger aircraft engine crash (diameter $2.7 \mathrm{~m}$, length $4.3 \mathrm{~m}$, weight 4.4 ton, impact velocity $90 \mathrm{~m} / \mathrm{s}$ ) has been examined. The reduced velocity is calculated by the local damage formula for concrete structure with its thickness of $70 \mathrm{~cm}$. The load vs. time function for this reduced velocity $(60 \mathrm{~m} / \mathrm{s})$ is estimated by the impact analysis using Finite Element code LS-DYNA with the full scale engine model onto a hypothetically rigid target. Secondly, as the most critical scenarios for the metal cask, two impact scenarios (horizontal impact hitting the cask and vertical impact onto the lid metallic seal system) are chosen. To consider the geometry of all bolts for two lids, the gasket reaction forces and the inner pressure of the cask cavity, the detailed three dimensional FEM models are developed and calculated. Main criteria for estimating the maximum leakage rate for the lid metallic seal system are no loss of the pre-stress of the lid bolts, no appearance of the plastic region between the metal seal flanges, and no large relative deformation of the lid seals. Finally, in both cases, the low leakage rate for the metal cask lid closure system under the impulsive loads due to aircraft engine crash will be proved thoroughly.
\end{abstract}

Key words: Metal Cask, Aircraft Crash, Nuclear Spent Fuel, Missile Impact, Metallic Seal, Interim Storage Facility 


\section{Introduction}

After the terrorist attacks from 11th September 2001, accident scenarios exceeding the design requirements, such as a forced aircraft crash, were considered, and the corresponding analysis have been executed with regard to the assessment of the inherent safety in an interim nuclear spent fuel storage facility with combined transport and storage casks. In Japan, the first interim storage facility of spent nuclear fuel away from reactor site is being planned to start its commercial operation around 2010, in use of dual-purpose metal cask in the northern part of Main Japan Island. To succeed early realization of the storage facility, it is important to present whether the forced aircraft crash event might lead a considerable release of radioactive substances into the environment integrity.

In this study, firstly, a penetrating engine of a big passenger aircraft, such as Boeing 747 and Air-Bus 300, was considered, since this engine covers the wide range of possible mechanical impacts. The assumed hitting speed of this aircraft engine was based on the reduced velocity after the penetration of the engine through the building. Secondly, two mechanical impact analyses onto the fuel storage metal cask using Finite Element code LS-DYNA with the full scale engine and cask model were executed to clarify the extent of reducing the cask integrity and the leakage increase.

\section{Impact analysis with the metal cask}

\subsection{Impact Scenarios}

With the object of clarifying the movements of the lid structure of the metal cask during the extreme impact loads due to aircraft crash, two impact scenarios for aircraft engine crash onto the metal cask without impact limiters as shown in Fig.1 were considered for both, a vertical impact onto the lid structure and a horizontal impact hitting the cask.

To evaluate the lid structure behavior during the extreme impact loads, impact analyses for these scenarios have been executed with dynamic Finite Element Method analysis code LS-DYNA Ver.970.

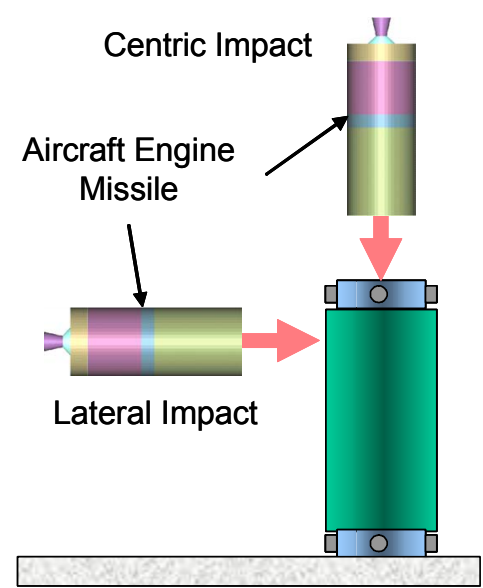

Fig. 1 Considered scenarios for aircraft engine crash onto the metal cask without impact limiters

\subsection{Impact Loading}

In order to analyze the movements of the lid structure of the metal cask in case of an impact due to a big passenger aircraft engine crash, a load vs. time function and a load contact area are needed. As a relevant aircraft engine, turbo-fan engine (Type GE/CF6-80C2), which was used for big passenger planes, such as Boeing747 and Air-Bus 300 , was chosen ${ }^{(7)-(9)}$. Fig.2 shows the outline of the relevant aircraft engine. Its length, outer diameter and weight are $2.7 \mathrm{~m}, 4.3 \mathrm{~m}$ and $4.4 \mathrm{ton}$, respectively. 
The local penetration damage of the interim storage facility building against a relevant aircraft engine crash has been examined. The impact velocity was set to $90 \mathrm{~m} / \mathrm{s}$ considering the taking-off, landing speed of the passenger aircraft, and the Type $\mathrm{C}$ package test conditions in the IAEA Transport Regulation ${ }^{(10)}$. The penetration depth can be calculated by the local damage formula, such as Degen formula for concrete structure ${ }^{(11)}$. Fig. 3 shows the relationship between the impact velocity and the penetration depth derived by Degen formula for rigid missile using the dimension of the relevant aircraft engine. For example, in case of the impact velocity $90 \mathrm{~m} / \mathrm{s}$, the protection thickness for the penetration of the concrete structure should be over $96 \mathrm{~cm}$. According to the design concept of the storage building $^{(5)}$, the wall thickness is set from $0.7 \mathrm{~m}$ to $1.2 \mathrm{~m}$. Therefore, the reduced velocity of the engine missile after the $85 \mathrm{~cm}$ wall thickness penetration can be estimated as about $60 \mathrm{~m} / \mathrm{s}$.

The load vs. time function for the relevant aircraft engine with this reduced velocity was estimated by the impact analysis using Finite Element code LS-DYNA with the direct full scale engine model onto hypothetical rigid target as shown in Fig.4.

Fig.5 shows the loading function. Impact loads were affected by the buckling of the nose corn, the interactive force between high and low pressure turbines, and the plastic deformation of the rotor spaced in the center of the engine. In the following impact analysis, the representative diameter of the impact load contact circular area was set to $1.4 \mathrm{~m}$ considering the stiffness distribution of the relevant aircraft engine.

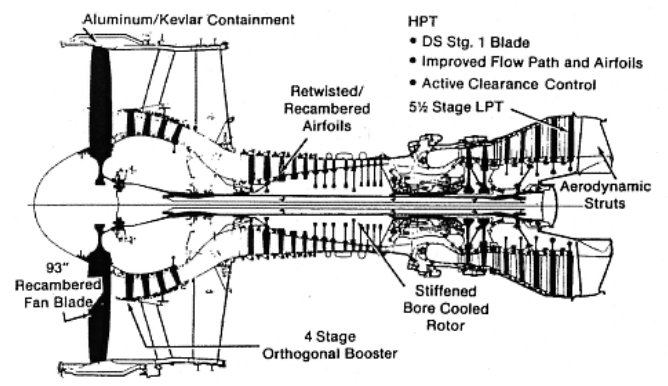

Fig. 2 Outline of the relevant aircraft engine (Type GE/CF6-80C2)

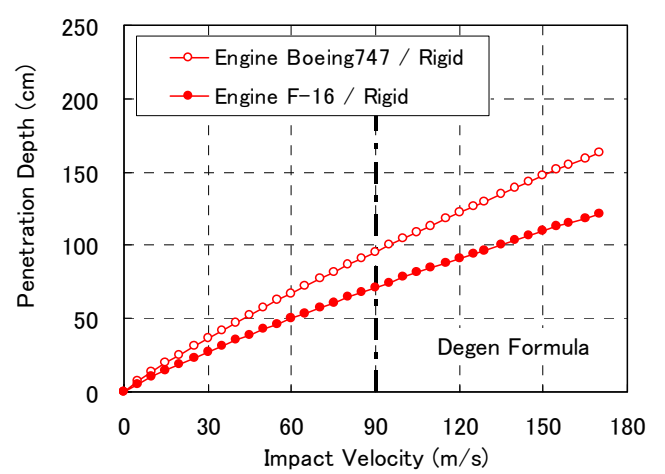

Fig. 3 Relationship between the impact velocity and the penetration depth (by Degen formula)

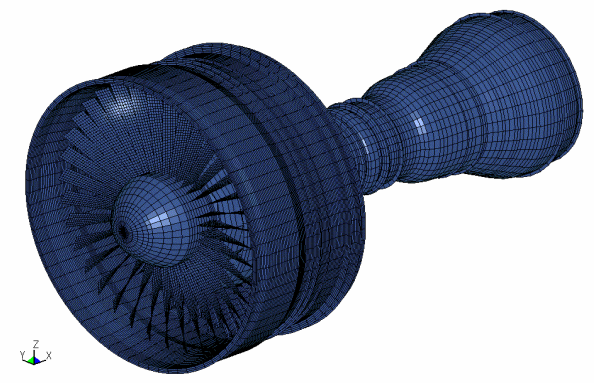

Fig. 4 Full scale engine model 


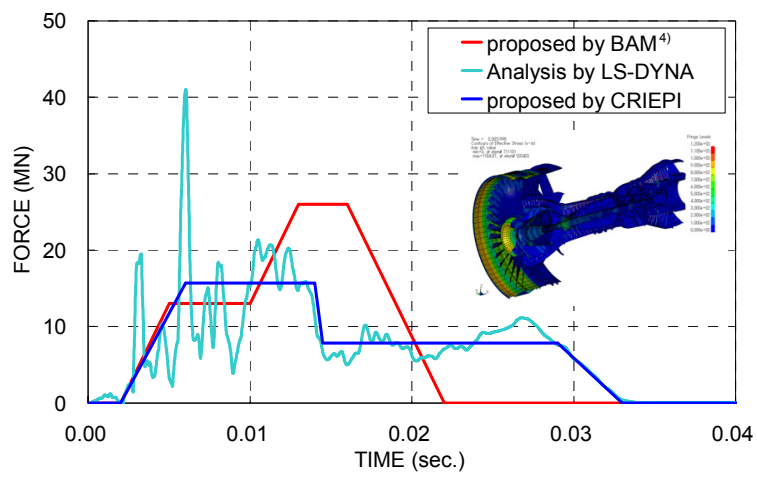

Fig. 5 Loading functions for the relevant aircraft engine

\subsection{Target storage cask description}

Fig.6 shows overview of a full-size metal cask model for impact analysis, and Table 1 shows main specifications of this model ${ }^{(12)}$. This model has been designed as metal cask for dry storage and transportation installing 21 PWR-type fuel assemblies.

This cask has double lid structure, and lid gaskets are double type metal gasket made of aluminum coating material. For primary and secondary lids, a section diameter of the gasket is $5.6 \mathrm{~mm}$ and $10 \mathrm{~mm}$, respectively. And this cask has a gap between lid side and body. At initial condition, primary and secondary lids are placed carefully to make the gap equal. Nominal gap of primary and secondary lids at one side is $1 \mathrm{~mm}$ and $0.5 \mathrm{~mm}$, respectively.

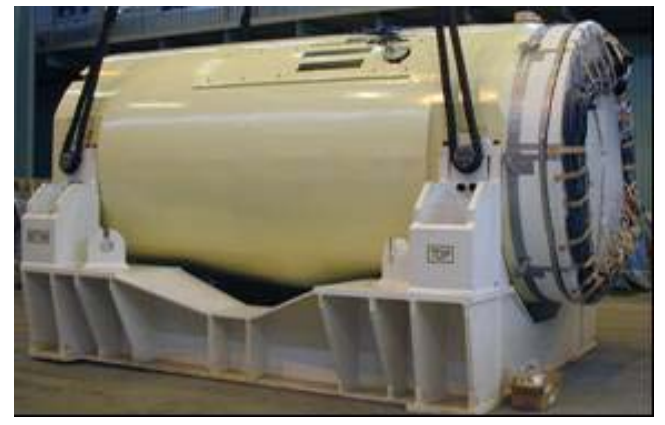

Fig. 6 Overview of full-size metal cask model

Table 1. Specification of Metal Cask Model

\begin{tabular}{|c|c|c|c|}
\hline Part & Material & Size (mm) & Weight (ton) \\
\hline Body & Carbon steel & Inner Dia. : 1672 & \multirow{6}{*}{84.6} \\
\hline & ASTM A350LF5 & Thickness : 250 & \\
\hline $\begin{array}{l}\text { Neutron } \\
\text { Shielding }\end{array}$ & Resin & Thickness : 164 & \\
\hline \multirow{2}{*}{ Outer Sell } & \multirow{2}{*}{ Carbon steel } & Outer Dia. : 2524 & \\
\hline & & Thickness : $\quad 12$ & \\
\hline Trunnion & $\begin{array}{l}\text { Stainless steel } \\
\text { SUS F630 }\end{array}$ & Diameter : & \\
\hline \multirow{2}{*}{ Primary Lid } & Carbon steel & Outer Dia. : 1946 & \multirow{2}{*}{4.2} \\
\hline & ASTM A350LF5 & Thickness : 198 & \\
\hline Secondary Lid & $\begin{array}{c}\text { Carbon steel } \\
\text { ASTM A350LF5 }\end{array}$ & $\begin{array}{l}\text { Outer Dia.: } 2236 \\
\text { Thickness : } 235.5\end{array}$ & 5.5 \\
\hline Contents & Equivalent weight & ------ & 24.7 \\
\hline \multicolumn{3}{|c|}{ Total Weight } & 119 \\
\hline
\end{tabular}




\subsection{Analysis model description}

Fig.7 shows analysis model of a vertical impact onto the lid structure and a horizontal impact hitting the cask. This model is made as a $1 / 2$ symmetric model considering the cask structure and the engine missile orientation. The accuracy of this analysis model was benchmarked by comparing the impact test results to simulate the impact behavior of the complicated gasketed joints ${ }^{(13)}$.

As to the contact condition, on every contact surface between parts of this analysis model, a slide surface condition with voids is applied. Friction coefficient of the slide surface is set to 0.14 . However, only for flange surface of primary and secondary lids, these coefficient values are set to experimental value (0.6) obtained from the sliding test result with a scaled lid model ${ }^{(12)}$. The initial tightening force of the lid bolts, equivalent to tightening torque of $2400 \mathrm{~N}-\mathrm{m}$, is set by the equilibrium condition with the forced initial contact displacement between the lid bolt and lid flange before the impulsive loading as shown in Fig.8.
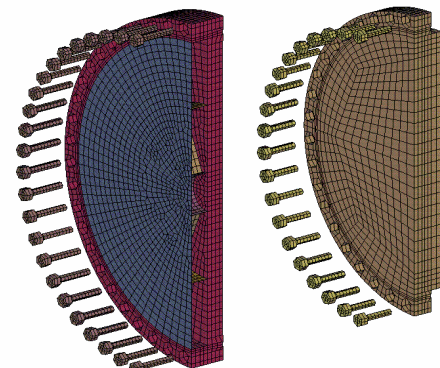

(Lids and Bolts)

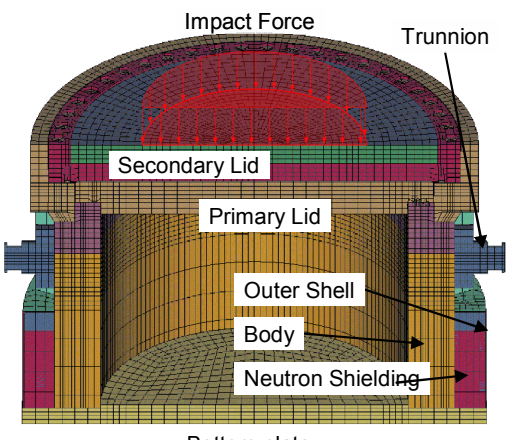

Bottom plate

(Vertical Impact)

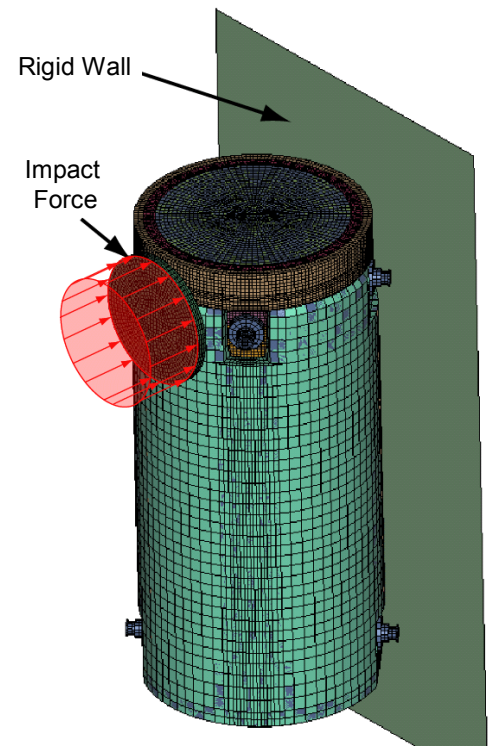

(Horizontal Impact)

Fig. 7 Analysis model for aircraft engine crash on to the cask

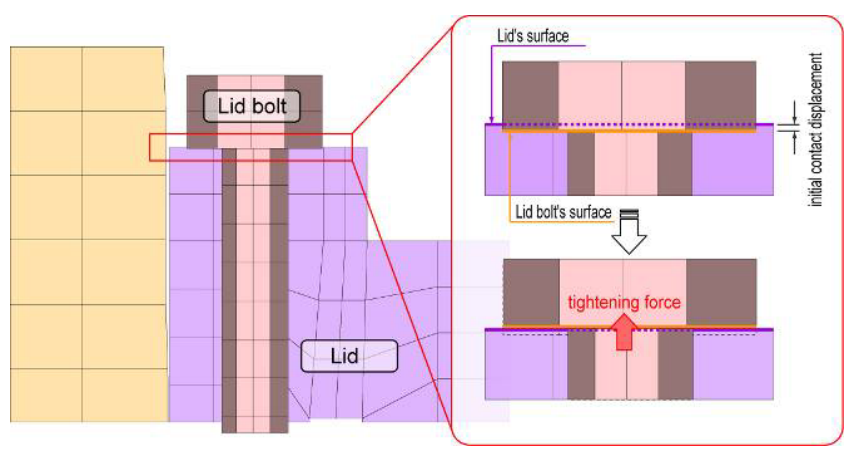

Fig. 8 Initial tightening force of the lid bolts

\subsection{Material properties}

Metallic materials are used for the cask body, lid, lid bolts, outer shell, trunnion, and contents. These materials are simulated as isotopic elastic plastic material. Table 2 shows 
material properties applied to the calculation. Strain rate effect was considered for yield stress.

Table 2. Material properties of the cask

\begin{tabular}{|c|c|c|c|c|c|}
\hline Part & $\begin{array}{c}\text { Density } \\
\left(\mathrm{kg} / \mathrm{m}^{3}\right)\end{array}$ & $\begin{array}{c}\text { Young's } \\
\text { modulus } \\
(\mathrm{MPa})\end{array}$ & $\begin{array}{c}\text { Poison's } \\
\text { ratio } \\
(---)\end{array}$ & $\begin{array}{c}\text { Yield } \\
\text { stress } \\
(\mathrm{MPa})\end{array}$ & $\begin{array}{c}\text { Hardening } \\
\text { modulus } \\
(\mathrm{MPa})\end{array}$ \\
\hline Body Lid & $7.85 \times 10^{3}$ & 203460 & 0.3 & $205^{*}$ & 2034 \\
\hline Lid bolt & $7.85 \times 10^{3}$ & 202000 & 0.3 & $890^{*}$ & 2020 \\
\hline Outer shell & $7.86 \times 10^{3}$ & 203000 & 0.285 & 215 & 2030 \\
\hline Trunnion & $7.86 \times 10^{3}$ & 195000 & 0.3 & $725^{*}$ & 1950 \\
\hline Contents & $7.86 \times 10^{3}$ & 203000 & 0.3 & 215 & 2030 \\
\hline
\end{tabular}

\section{Containment evaluation criteria}

Containment evaluation criteria for the metal gasket seal was proposed by Japan Nuclear Energy Safety Organization (JNES), based on a series of leakage tests using scale models with double type aged metal gasket made of aluminum coating material of which section diameter was $10 \mathrm{~mm}^{(14)}$. Sliding or opening of the lid is defined by the relative displacement of the metallic gaskets parallel or normal to the flange, respectively as shown in Fig.9. The accumulated relative displacement $\mathrm{D}_{\mathrm{S} \text {,Accumulated }}$ is defined by subtracting the difference between the values of initial and residual, $D_{\mathrm{S}, \text { Resiual }}-\mathrm{D}_{\mathrm{S} \text {, Initial }}$ from twice the difference between maximum and minimum, $2 *\left(D_{\mathrm{S}, \text { Max. }}-\mathrm{D}_{\mathrm{S}, \text { Min. }}\right)$.

The instantaneous leak rate for 60-year aged metal gasket seal subjected to the impulsive loads could be evaluated by the relationship between the leak rate and $\mathrm{D}_{\mathrm{S}, \text { Accumulated }}$ as shown in Fig.10, if the lid system would satisfy the following conditions.

* There is no plastic deformation in the lid system.

* There is no considerable opening of the lids.

* There is no considerable loss of the torque of the lid bolts.

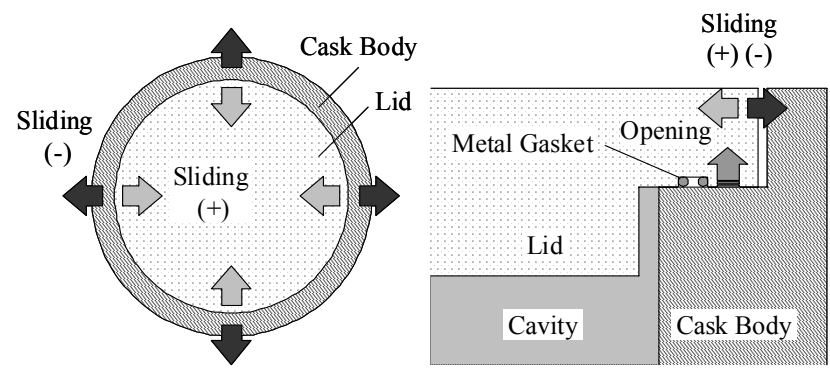

Fig. 9 Definition of the Sliding or Opening of the Lids
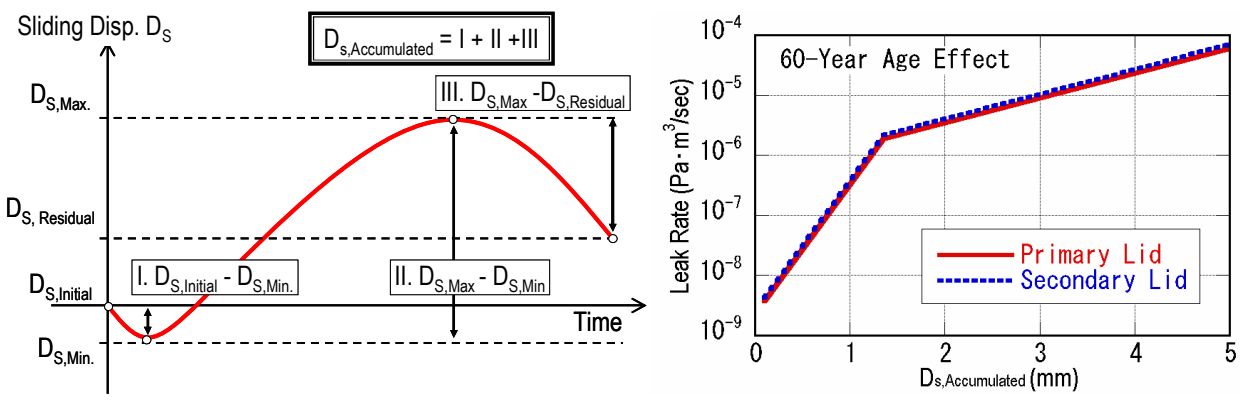

Fig. 10 Relationship between the leak rate and the accumulated relative displacement 


\section{Impact analysis results}

\subsection{Plastic deformation}

Fig.11 shows the generation of the plastic deformation in each scenario. In case of the vertical impact onto the lid metallic seal system, the plastic deformation was generated in the second lid flange, therefore the leak-tightness of the secondary lid system might be lost during impact loads according to the leakage criteria described above. On the other hand, there is no plastic deformation in the lid system in case of the horizontal impact hitting the cask.

\subsection{Lid Movements}

Fig.12 and Fig.13 show the example of the time history of the lid movements during the vertical impact onto the lid metallic seal system and the horizontal impact hitting the cask. In case of the vertical impact, a considerable lid opening displacement was generated in the secondary lid. On the other hand, in case of the horizontal impact, the large sliding deformations of the primary and secondary lids were generated.

\subsection{Evaluation of Leak-tightness}

Table 3 shows the summary of the impact analysis results. According to the leakage criteria described above, it can be concluded that the leakage rate from the primary lid might be considerably low (less than $1.0 \times 10^{-5} \mathrm{~Pa} \cdot \mathrm{m}^{3} / \mathrm{s}$ ), and the loss of the inner pressure in the cask might be avoided during the extreme impact loading due to aircraft engine crash scenarios.

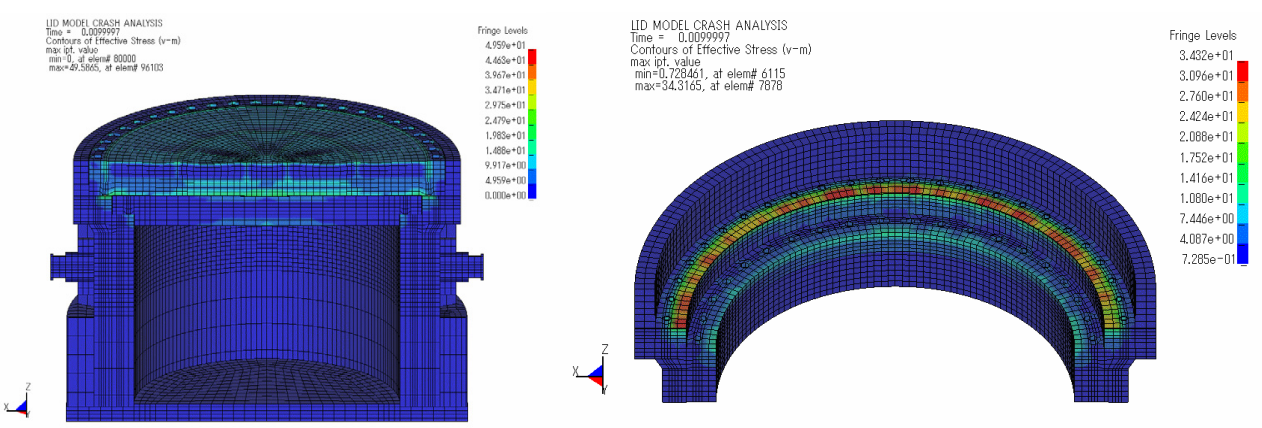

(Vertical impact)

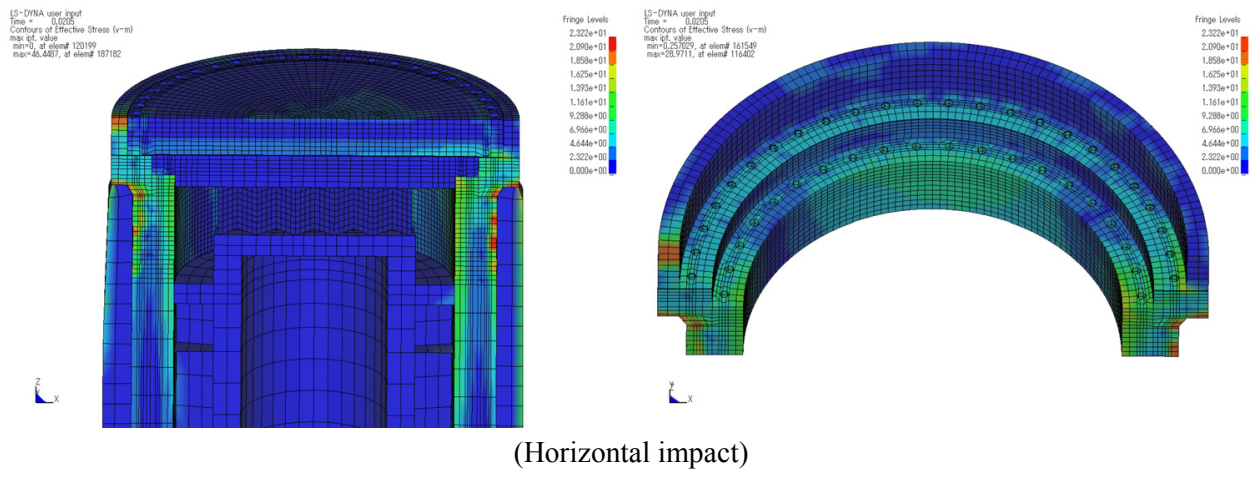

Fig. 11 Generation of plastic deformation in each scenario 


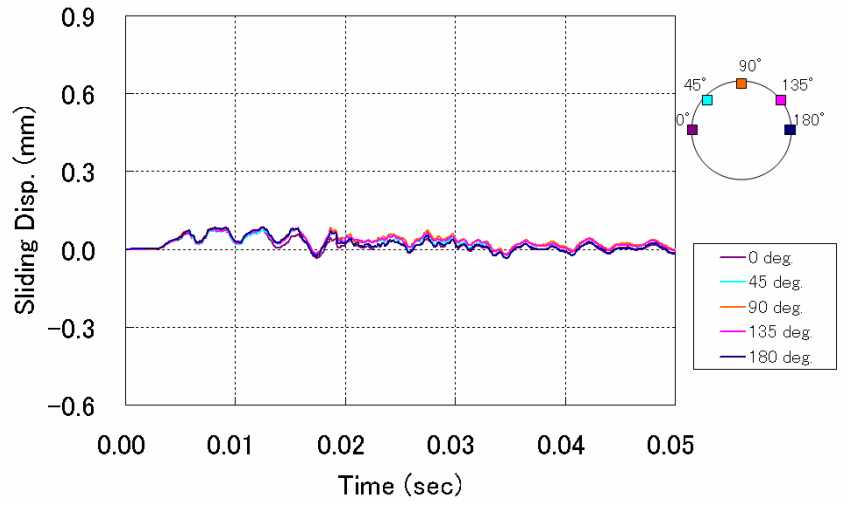

(Sliding displacement of the primary lid)

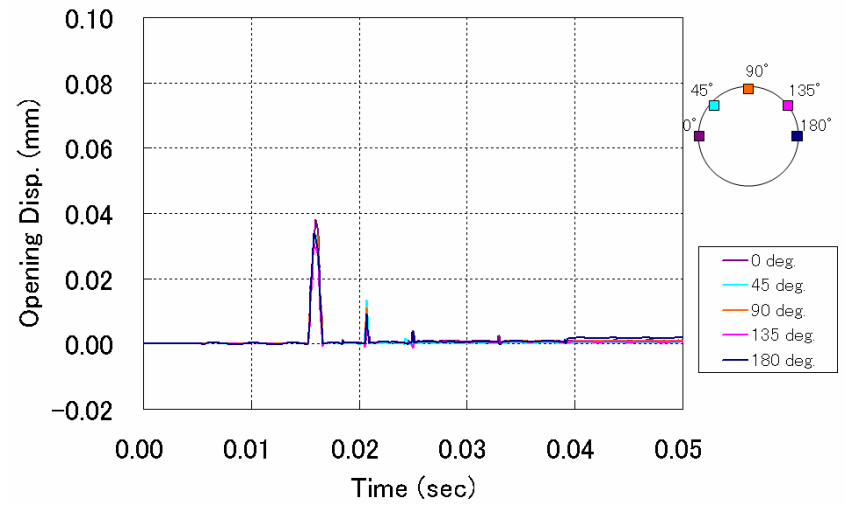

(Opening displacement of the primary lid)

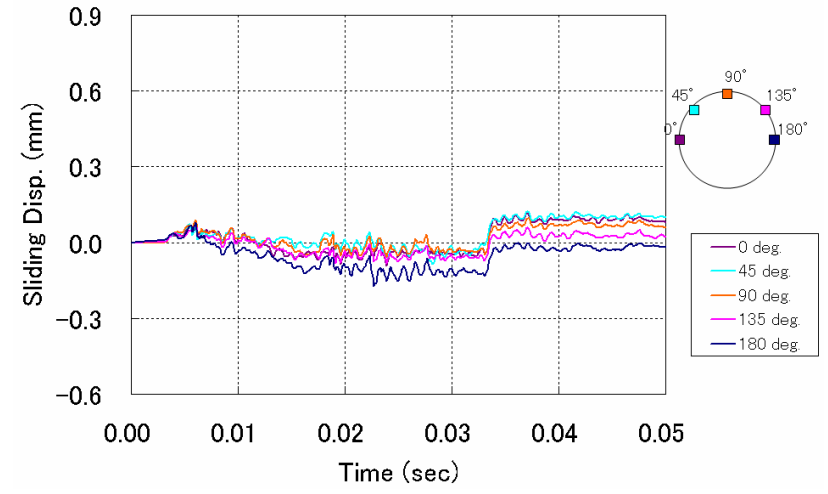

(Sliding displacement of the secondary lid)

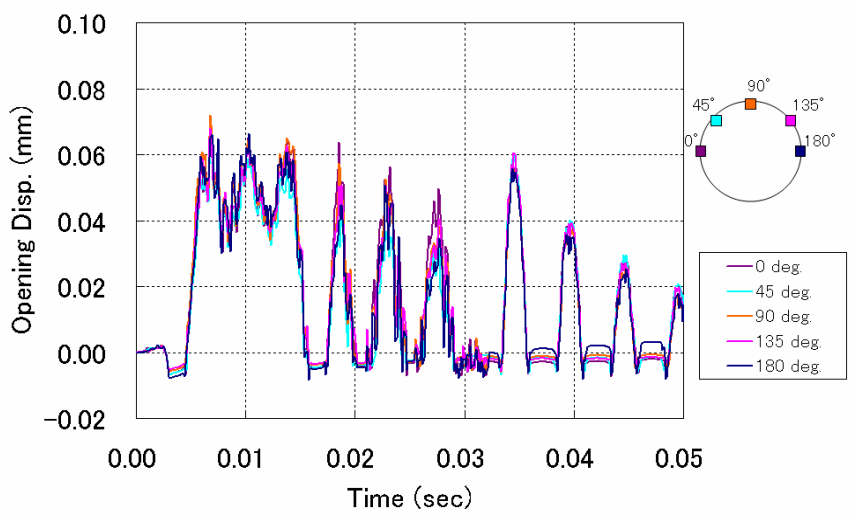

(Opening displacement of the secondary lid)

Fig. 12 Time histories of the displacement of the lids for the vertical impact scenario 


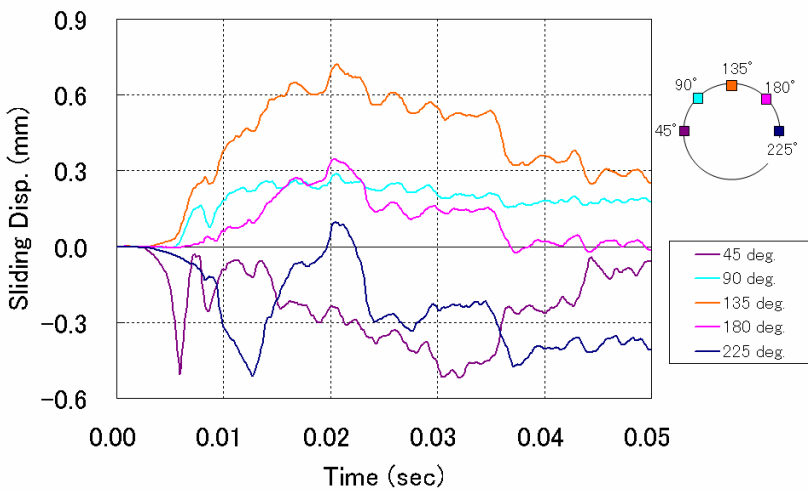

(Sliding displacement of the primary lid)

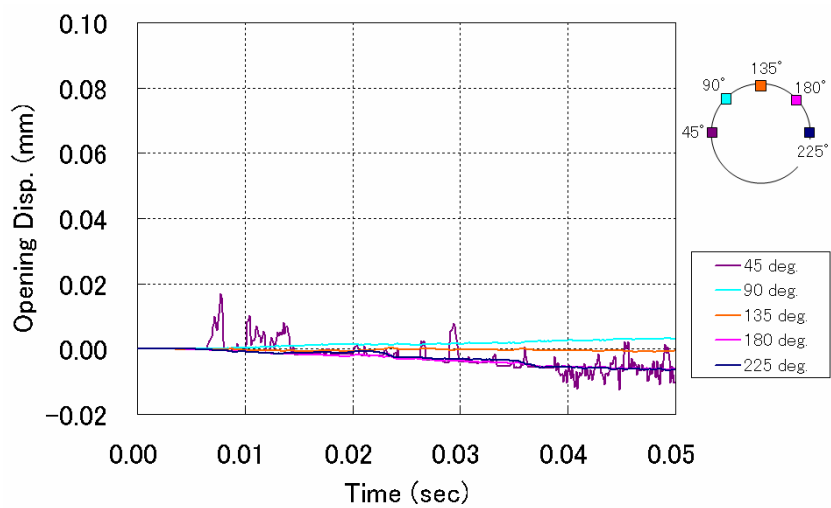

(Opening displacement of the primary lid)

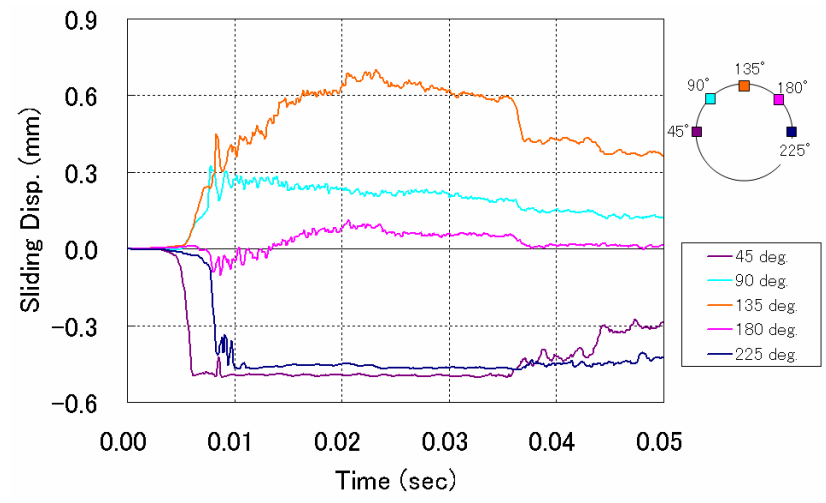

(Sliding displacement of the secondary lid)

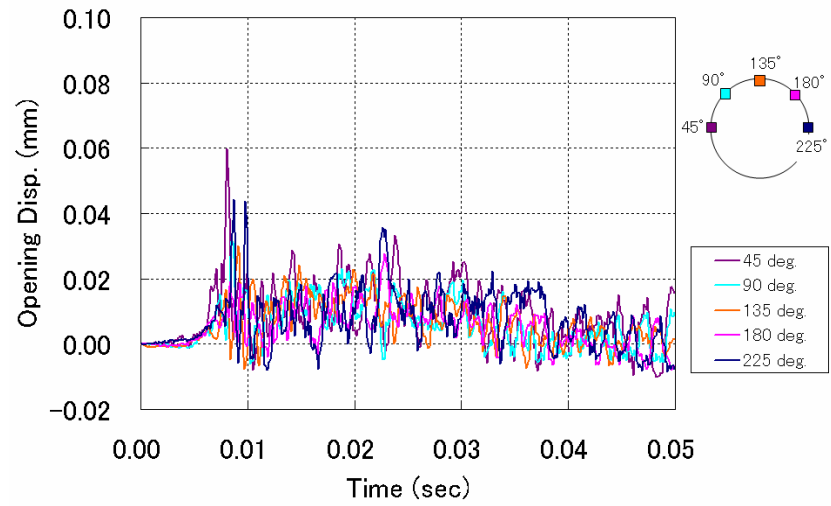

(Opening displacement of the secondary lid)

Fig. 13 Time histories of the displacement of the lids for the horizontal impact scenario 
Table 3. Summary of the Impact Analysis

\begin{tabular}{|c|c|c|c|}
\hline \multicolumn{2}{|c|}{ Event } & Vertical impact & Horizontal impact \\
\hline \multirow{3}{*}{ Part } & Sliding* & $0.23 \mathrm{~mm}$ & $1.70 \mathrm{~mm}$ \\
\cline { 2 - 4 } & Opening & $0.04 \mathrm{~mm}$ & $0.02 \mathrm{~mm}$ \\
\cline { 2 - 4 } & Status** & None & None \\
\hline \multirow{3}{*}{\begin{tabular}{c} 
Secondary lid \\
\cline { 2 - 4 }
\end{tabular}} & Sliding* & $0.52 \mathrm{~mm}$ & $1.77 \mathrm{~mm}$ \\
\cline { 2 - 4 } & Opening & $0.07 \mathrm{~mm}$ & $0.06 \mathrm{~mm}$ \\
\cline { 2 - 4 } & Status*** & No plastic & No plastic \\
\hline $\begin{array}{c}\text { Estimated Leak Rate } \\
\left(\mathrm{Pa}^{3} / \mathrm{m}^{3} / \mathrm{s}\right)\end{array}$ & Primary lid & $<1.0 \times 10^{-5}$ & $<1.0 \times 10^{-5}$ \\
\cline { 2 - 4 } & Secondary lid & Loss & $<1.0 \times 10^{-5}$ \\
\hline
\end{tabular}

* Accumulated Sliding Displacement

** Generation of the plastic deformation in the lid system

\section{Conclusions}

The analyses of two impact scenarios for aircraft engine crash onto the metal cask without impact limiters, a vertical impact onto the lid structure and a horizontal impact hitting the cask, have been executed to clarify the extent of reducing the cask integrity and the leakage increase.

The leakage rates were calculated in connection with the determination of the accumulated relative displacements between the metallic gaskets and the flange.

After the lid behaviors in each scenario have been evaluated, it was found that although the secondary lid might lose the leak-tightness in case of the vertical impact, the leakage rate from the primary lid might be low and the loss of the inner pressure inside the cask might be avoided in the extreme impact loading conditions.

\section{Acknowledgments}

These works have been carried out under the contract from Nuclear and Industrial Safety Agency, Ministry of Economy and Trade Industry of the Japanese Government.

\section{References}

(1) K. Shirai, et al., "Experimental Studies of Free-Standing Spent Fuel Storage Cask subjected to Strong Earthquake", PATRAM 2007, Miami, Florida, USA (2007).

(2) K. Shirai, et al., "Confinement Analysis of Dual Purpose Metal Cask subjected to Impulsive Loads during Handling Accidents", PATRAM 2007, Miami, Florida, USA (2007).

(3) US. NRC, Containment Integrity Research at Sandia National Laboratories, -An Overview-, NUREG/CR-6906, July, (2006).

(4) Nuclear Energy Institute, DETERRING TERRORISM: Aircraft Crash Impact Analyses Demonstrate Nuclear Power Plant's Structural Strength, (2002).

(5) B.R. Thomauske, "Realization of the German concept for interim storage of spent nuclear fuel -Current situation and prospects- “, WM'03 Conference, Tucson, AZ, USA, (2003).

(6) Günter Wieser, L. Qiao, H. Völzke, D. Wolff and B. Droste, "Safety analysis of casks under extreme impact conditions", PATRAM 2004, Paper \#208, Berlin, Germany, Sept., (2004).

(7) Boeing 747 Family: Technical, http://www.boeing.com/ commercial/747family/technical. html 
(8) CINDAS/USAF CRD Purdue Univ., Aerospace Structural Metals Handbook, Vol.4, Code 4103, (1995).

(9) CINDAS/USAF CRD Purdue Univ., Aerospace Structural Metals Handbook, Vol.4, Code 3707, (2000).

(10) INTERNATIONAL ATOMIC ENERGY AGENCY, Regulations for the Safe Transport of Radioactive Material, Safety Requirements No.TS-R-1, 2005 Edition, IAEA, Vienna (2005).

(11) Degen P.P., "Perforation of reinforced concrete slabs by rigid missiles, Journal of the Structural Division, Proceedings of ASCE, Vol.106. No.ST7, July, (1980).

(12) Takeda, H., et.al., " Leakage Evaluation of Metal Cask during Drop Test ", Proc. of GLOBAL 2005, No.575, Tsukuba, Japan, (2005).

(13) Kageyama, N., et al., Numerical Studies on Impact Tests of Full-Size Metal Storage Cask, 9th International Conference on Structures Under Shock and Impact, SUSI IX, New Forest, United Kingdom, June, (2006).

(14) T. Yokoyama, et al., "Integrity Assessment of Dual-Purpose Metal CASK after Long Term Interim Storage-Seal Performance under Transport Condition”, PATRAM2004, Berlin, Germany, (2004). 